\title{
Operations of the National Weather Service Spaceflight Meteorology Group
}

\author{
Frank C. Brody, Richard A. Lafosse, and Dan G. Bellue \\ Spaceflight Meteorology Group, Johnson Space Center, Houston, Texas \\ TIMOTHY D. ORAM \\ United Space Alliance, Johnson Space Center, Houston, Texas \\ (Manuscript received 1 January 1996, in final form 3 November 1996)
}

\begin{abstract}
Weather is a significant aspect of most space shuttle launches and landings. The National Weather Service Spaceflight Meteorology Group (SMG) at Johnson Space Center (JSC) in Houston, Texas, provides weather forecasts and advice to support space shuttle operations. SMG has been an integral part of the flight control team in the Mission Control Center at JSC since 1962. Space shuttle weather support is quite complex and specialized, especially compared to more traditional weather forecast operations. SMG forecasts are compared to shuttle weather flight rules to advise the flight director on launch and landing decisions. Perhaps the most critical aspect of SMG's weather support is the "90-min forecast" issued prior to landing, supporting the Mission Control Center's "go" or "no-go" deorbit burn decision. Once the deorbit burn has occurred, the shuttle must land at the designated landing site at the designated time. SMG's forecast must be precise, accurate, and clearly communicated.

Meteorological data acquisition and display is critical for analysis and forecasting, and for briefing the flight control team. Primary systems used are the Meteorological Interactive Data and Display System and the Weather Surveillance Radar-1988 Doppler Principal User Processor.

This article describes SMG functions, operations, data acquisition and display systems, and shuttle launch and landing weather forecast scenarios.
\end{abstract}

\section{Introduction}

The National Weather Service (NWS) Spaceflight Meteorology Group (SMG) provides weather forecasts and briefings to support space shuttle operations of the National Aeronautics and Space Administration (NASA). SMG provides forecasts for surface and upperair parameters for all potential shuttle landing sites, from postlaunch abort contingencies at U.S. and overseas landing sites, to the final end-of-mission (EOM) landing at Kennedy Space Center (KSC) Florida, or Edwards Air Force Base (EDW), California. SMG is an integral part of the Mission Control Center (MCC) flight control team at NASA's Johnson Space Center (JSC) in Houston, Texas.

Weather is a significant aspect of most shuttle launch and landing decisions. An internal study of 30 missions between 1991 and 1995 found that $80 \%$ of all launch and landing countdowns (i.e., within $6 \mathrm{~h}$ of launch or landing) encountered shuttle landing weather flight rules

Corresponding author address: Frank C. Brody, Spaceflight Meteorology Group, Johnson Space Center, Mail Code ZS8, Houston, TX 77058.

E-mail: frank.brody@jsc.nasa.gov
(NASA/JSC, 1997) violations. These violations were either observed during the countdown, forecast to occur, or were both observed and forecast.

Shuttle weather support operations are extremely complex due to the highly specialized nature of shuttle weather support requirements, relatively restrictive launch and landing time frames and weather constraints, and the extensive coordination and planning required to ensure complete meteorological support. SMG forecasts range from the microscale to hemispheric scale. NASA requires short- to medium-range (1-6 day) forecasts for mission planning and precise short-term $(0-12 \mathrm{~h})$ forecasts to ensure safety of the shuttle flight during the critical landing and prelanding phases. The ability to provide this critical support depends on forecasters' skill and experience, the capabilities for ingesting and displaying large volumes of high-resolution weather data, and a capacity to work effectively as part of a decisionoriented flight control team. This article describes SMG operations, technologies, and analysis and forecast techniques used to provide this support.

Section 2 of this paper describes space shuttle weather support. Section 3 describes data acquisition and display. Brief case studies of mission support scenarios are listed in section 4 . 


\section{Space shuttle weather support}

\section{a. Forecast responsibilities}

SMG's lead forecasters have final responsibility for shuttle landing weather forecasts and advice to the NASA flight director, flight control team, and mission management team (MMT). This includes EOM landing forecasts as well as launch-day forecasts for return-tolaunch-site (RTLS) landings, transoceanic abort landings (TAL), abort-once-around (AOA) landings, and first-day PLS landings (Brody 1993). Lead forecasters rotate through assignments as the "lead" and "assistant lead" forecaster for each shuttle mission. SMG's technique development unit (TDU) meteorologists are also computer specialists whose primary functions include customizing SMG's MIDDS system for operational weather support, performing computer systems management, and working operational mission support shifts.

While SMG has forecast responsibility for all shuttle landings and potential landings, the U.S. Air Force 45th Weather Squadron (45WS) at Cape Canaveral Air Station (CCAS) provides weather support for shuttle launches from Kennedy Space Center (Boyd et al. 1995). Since launch and RTLS are separated in time by about $25 \mathrm{~min}$ and in distance by about $3 \mathrm{mi}$ (i.e., launch pad vs landing runway), extensive coordination occurs between SMG and 45WS prior to each shuttle launch. The division of forecast responsibility is due to 1) the difference between weather launch commit criteria (LCC) (NASA/JSC 1997b) for launches and weather flight rules (NASA/JSC 1997) for landings, and 2) the inherent advantage of "dedicated" on-site support for NASA's launch and landing decision makers. 45WS directly supports the launch director and Launch Control Team at KSC, whereas SMG directly supports the flight director and flight control team at JSC. Command and control of the shuttle switches to the JSC Mission Control Center when the shuttle clears the launch pad. All in-flight and landing decisions are made by the JSC Flight Control Team, led by the flight director.

Training and certification are critical aspects of SMG operations. NASA has strict certification requirements for all shuttle flight controllers. As members of the flight control team, SMG meteorologists must meet certification requirements that consist of a combination of meteorological experience, mission support training, and computer systems proficiency.

Between missions, NASA trains flight controllers almost daily via a variety of "simulations." SMG participates in ascent (launch) and entry (landing) Flight Control Team simulations, supplying weather forecasts and briefings for shuttle landing sites. These flight control simulations promote improved interaction and integration with the flight control team and provide operational training for SMG meteorologists. Additionally, SMG prepares and verifies daily forecasts for shuttle landing sites between missions (Bellue 1993). These forecasts are for projections of $30 \mathrm{~min}$ (for the RTLS site and TAL sites), $90 \mathrm{~min}$ (EOM sites), $15 \mathrm{~h}$ (RTLS, TAL, EOM sites), and $24 \mathrm{~h}$ (RTLS, TAL, EOM sites). The experience gained through these daily forecasts is critical for successful shuttle landing weather support.

During and between shuttle missions, SMG provides pilot weather briefings to astronauts for their training flights. SMG provides advisories on the following weather events that will affect the JSC facilities in Houston: lightning within $5 \mathrm{n} \mathrm{mi}$, heavy/excessive rains, high winds $(>30 \mathrm{kt})$, severe thunderstorms, tornadoes, freezing or frozen precipitation, tropical depressions, tropical storms, and hurricanes. Advisories are provided to a variety of weather sensitive operations within Johnson Space Center and to NASA's Ellington Field, about 5 n mi northwest of JSC. When tropical storms or hurricanes threaten the Houston-Galveston area, SMG weather advisory support to JSC continues until the decision is made to close JSC or until the threat has ended. SMG's forecasts and advice to JSC management are critical factors in their decision processes on whether and when to close JSC.

SMG is the staff weather office for Johnson Space Center. SMG meteorologists participate in evaluations of weather-related issues, such as proposed weather flight rules changes, landing site instrumentation upgrades, and landing site climatology. SMG provides documentation of shuttle landing weather forecasts and observations, and participates in postlanding analyses of weather-related shuttle performance. SMG meteorologists conduct formal weather training courses for flight directors, flight controllers, and astronauts. Informal training occurs frequently as NASA personnel visit SMG to obtain forecasts, outlooks, and briefings, and to discuss launch or landing strategies. In addition, SMG collaborates with the NASA Applied Meteorology Unit (Ernst et al. 1995).

\section{b. Types of landings}

Space shuttle operations require the option for several types of landing scenarios, which are summarized in Table 1. RTLS would occur if the shuttle experiences a major problem within about the first 3 min of ascent. An RTLS landing requires the shuttle to turn, descend, and land at the Shuttle Landing Facility (SLF) at KSC, $3 \mathrm{n}$ mi west of the launch pad. This landing would occur about $25 \mathrm{~min}$ after launch. A TAL would occur if the shuttle experienced a major problem within the first 8 min of flight. In the TAL scenario, the shuttle would descend and land at one of the predesignated shuttle TAL sites: Zaragoza, Spain; Moron, Spain; Ben Guerir, Morocco; or Banjul, The Gambia. A TAL landing would occur approximately $35 \mathrm{~min}$ after launch. Two other launch abort landing scenarios include AOA and 1st Day PLS. These landings may be directed by the flight director if a major problem occurs early in the "on-orbit" phase of the shuttle flight. An AOA landing would occur 
TABLE 1. Space shuttle landing scenarios.

\begin{tabular}{|c|c|c|c|}
\hline Landing type & Time after launch* & Location(s) & Weather required for shuttle launch/landing \\
\hline RTLS & $25 \mathrm{~min}$ & $\mathrm{KSC}$ & Obs and fcst go \\
\hline TAL & $35 \mathrm{~min}$ & $\begin{array}{l}\text { Zaragoza, Spain } \\
\text { Moron, Spain } \\
\text { Ben Guerir, Moroc̀co } \\
\text { Banjul, The Gambia }\end{array}$ & Obs and fcst go at $\geq$ one TAL site \\
\hline $\mathrm{AOA}$ & $105 \mathrm{~min}$ & $\begin{array}{l}\text { EDW } \\
\text { WSSH } \\
\text { KSC }\end{array}$ & No constraints \\
\hline 1st day PLS ${ }^{* *}$ & $3-10 \mathrm{~h}$ & $\begin{array}{l}\text { EDW } \\
\text { WSSH } \\
\text { KSC }\end{array}$ & Fcst go for designated PLS landing time \\
\hline EOM & $7-16$ days & KSC, EDW, WSSH & Obs and fest go \\
\hline
\end{tabular}

about 105 min after launch at one of the U.S. landing sites: KSC, EDW, or WSSH. A 1st Day PLS could occur between the third and seventh orbits, or from about 3 through $10 \mathrm{~h}$ after launch, depending on the inclination of the flight and available landing opportunities. A 1st Day PLS landing would occur at KSC, EDW, or WSSH. On-orbit PLS selection involves the Flight Control Team predesignating a U.S. landing site (based on runway conditions and the weather forecast) for planning in case the shuttle experienced a problem requiring it to deorbit quickly and land. EOM is the scheduled, planned landing to conclude the shuttle mission. SMG issues forecasts and detailed weather briefings for all shuttle landing scenarios. For EOM landings, KSC is normally the preferred shuttle landing site. Figure 1 displays landing site locations. Figure 2 shows TAL site locations.

\section{c. Weather flight rules}

Shuttle weather flight rules are designed to ensure safety of flight and take into account the maneuverability constraints of the shuttle, slant range (diagonal) visibility considerations, protection against tile damage, and protection against lightning and triggered lightning. Shuttle weather flight rules are much more restrictive than flight rules for commercial or general aviation. For example, certain commercial aircraft at airports with advanced navigational aids have no ceiling or visibility restrictions, whereas Shuttle end-of-mission landing limits at KSC are ceilings of at least $8000 \mathrm{ft}$ and visibility of at least 5 statute miles. Also, shuttle weather flight rules stipulate no rain or thunderstorms (including anvils) within $20 \mathrm{n} \mathrm{mi}$ for RTLS and TAL, or within $30 \mathrm{n} \mathrm{mi}$ for EOM. Table 2 shows a set of flight rules for a daylight shuttle EOM landing at Kennedy Space Center. Multiple variations exist in shuttle weather flight rules for different landing sites and landing scenarios (e.g., day vs night, EDW vs KSC, RTLS vs EOM).

In order for the shuttle to launch, weather conditions must be observed and forecast "go" (i.e., within limits established by the shuttle weather flight rules) at the RTLS site and at least one TAL site, and must be forecast go at the 1st Day PLS site. Additionally, the weather must be observed go at launch time with respect to shuttle launch commit criteria as monitored by $45 \mathrm{WS}$. For landing, weather conditions must be observed and forecast go at the designated site. During launch and landing counts, SMG forecasts are compared directly to the weather flight rules to assess if conditions are go or no go. The NASA flight director at JSC has the final decision-making authority for evaluating weather flight rules and making launch recommendations or landing decisions based on these rules. In practice, the flight director relies heavily on SMG meteorologists for

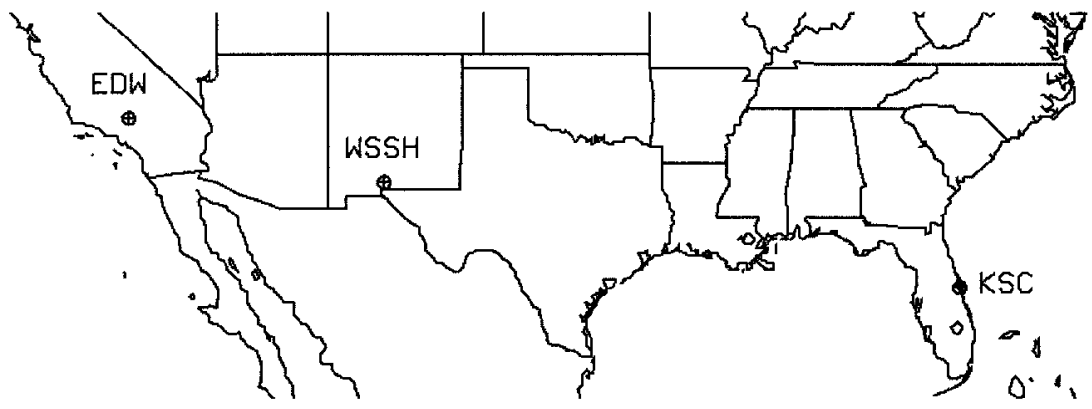

FIG. 1. U.S. shuttle landing sites: KSC = Kennedy Space Center, FL; WSSH = White Sands Space Harbor, NM; EDW = Edwards Air Force Base, CA. 


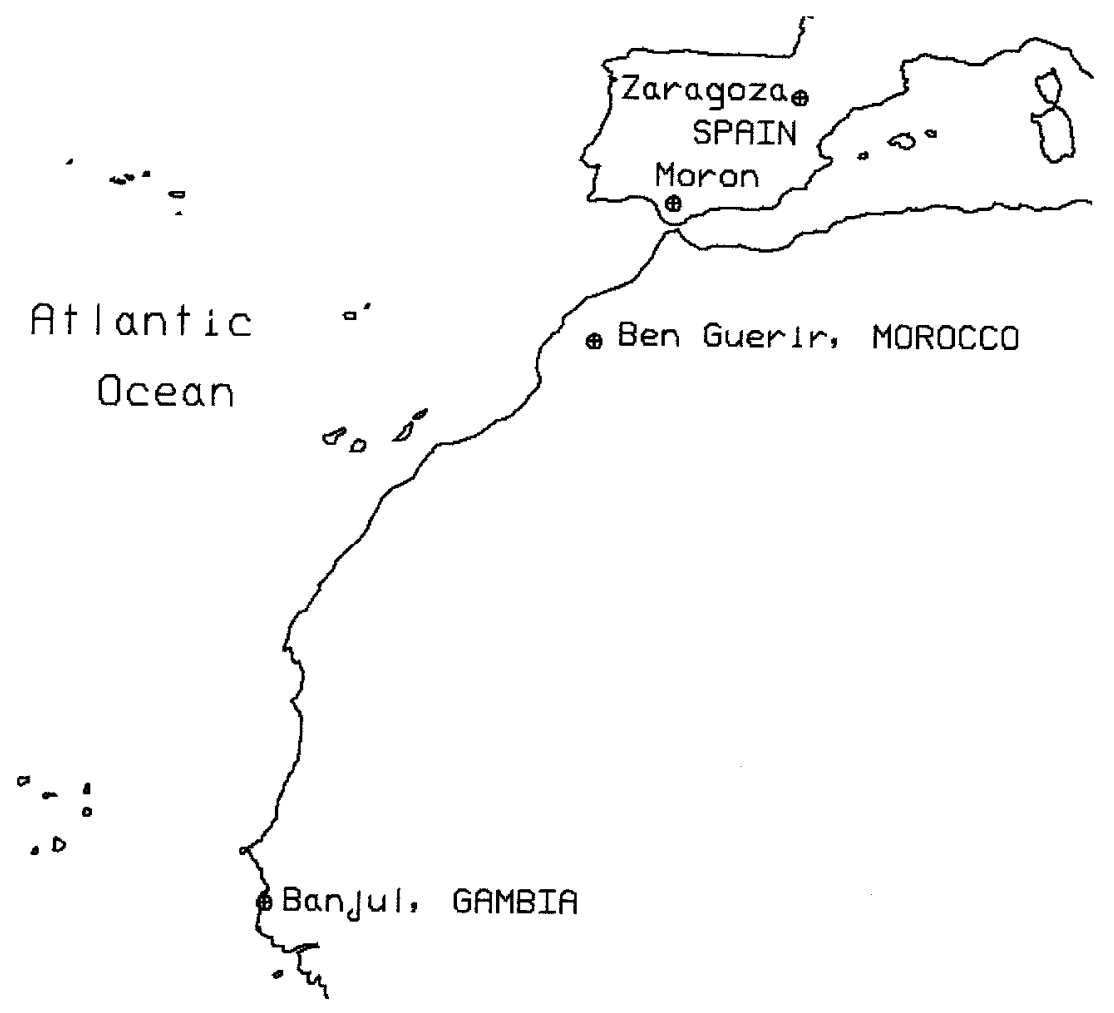

FIG. 2. Transoceanic abort landing (TAL) sites.

weather advice and recommendations with respect to these flight rule-based decisions.

\section{d. SMG forecasts and briefings}

SMG's formal weather forecast support to NASA begins 2 days before launch and continues throughout the mission until the shuttle lands. Forecasts describe clouds, visibilities, precipitation, winds, and turbulence. In addition, upper-air wind forecasts are issued for altitudes up to $80000 \mathrm{ft}$. Temperature, altimeter setting, and density altitude forecasts are issued within $6 \mathrm{~h}$ of

TABLE 2. Space shuttle weather flight rules: daylight end-ofmission (EOM) landing at Kennedy Space Center.*

\begin{tabular}{lc}
\hline \hline \multicolumn{1}{c}{ Parameter } & Limits \\
\hline Cloud ceiling height & $8000 \mathrm{ft}$ \\
Visibility & $5 \mathrm{n} \mathrm{mi}$ \\
Crosswind-peak & $15 \mathrm{kt}$ \\
Headwind-peak & $25 \mathrm{kt}$ \\
Tailwind-peak & $15 \mathrm{kt}$ \\
Tailwind-average & $10 \mathrm{kt}$ \\
Average vs. peak wind & $10-\mathrm{kt}$ difference \\
Precipitation & Not within $30 \mathrm{n} \mathrm{mi}$ \\
Thunderstorms including anvil & Not within $30 \mathrm{n} \mathrm{mi}$ \\
Detached opaque anvil less than $3 \mathrm{~h}$ old & Not within $20 \mathrm{n} \mathrm{mi}$ \\
Turbulence & Moderate \\
\hline
\end{tabular}

* Flight rules vary depending on landing site, day vs night, type of landing, mission duration, and landing navaids available. launch and landing. Figures 3 and 4 show examples of SMG forecasts. Weather briefings typically include a brief synoptic explanation, the forecast rationale, and, when applicable, alternate weather scenarios. Briefings highlight the timing of anticipated weather events during launch "windows" and, for EOM landings, they describe how the weather might impact decisions for all landing sites and landing opportunities.

\section{e. Mission support timelines}

Planning and coordination for a shuttle mission begins about 5 weeks before the scheduled launch. Documentation and follow-up work may continue for 1-3 months after landing, depending on the complexity of the weather events associated with the mission and the number of operational issues to be resolved. Table 3 lists an abbreviated SMG mission support timeline for a shuttle reentry and landing. The following sections briefly highlight important phases of the prelaunch, on-orbit, and prelanding support timelines.

\section{1) Prelaunch Support}

All prelaunch briefings include forecasts for RTLS at the KSC Shuttle Landing Facility (SLF), TAL sites, the AOA sites, and the 1st Day PLS sites. The first formal prelaunch weather briefing is conducted at the " $\mathrm{L}-$ 2 " day MMT briefing, usually about $48 \mathrm{~h}$ prior to 


\section{STS - 74 LAUNCH}

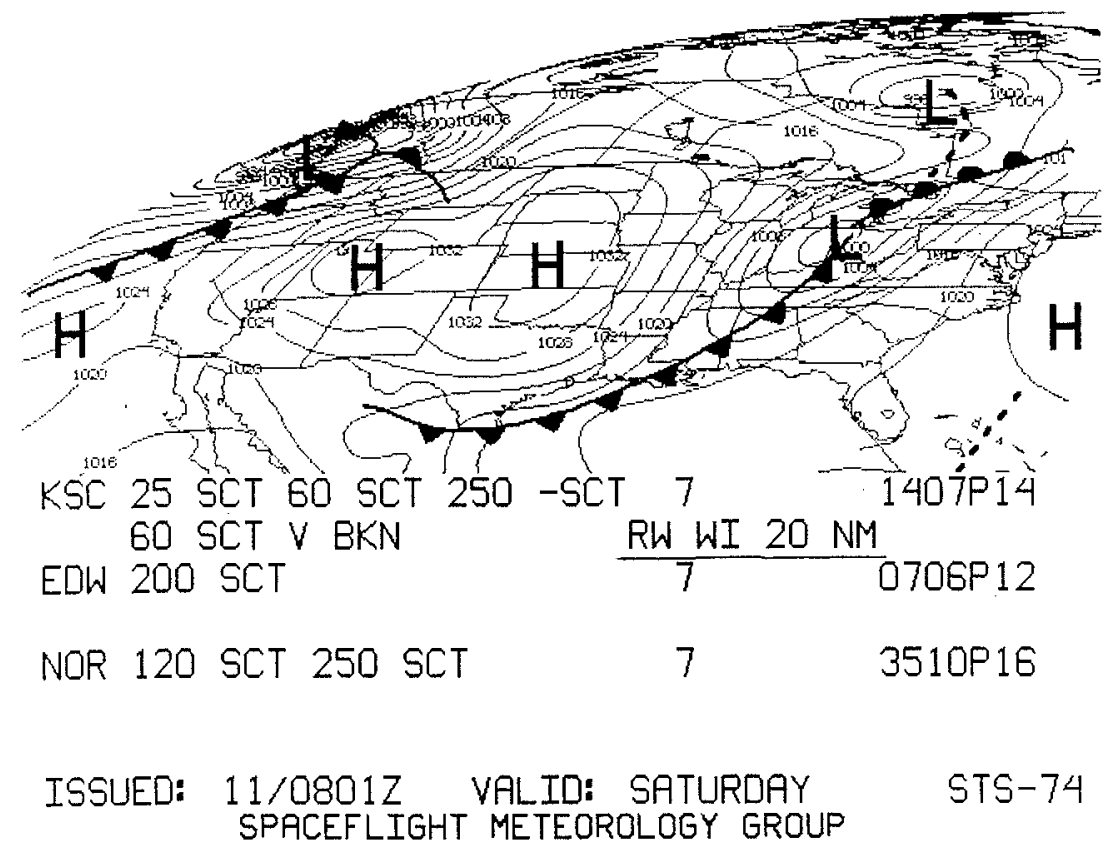

STS - 74 LAUNCH

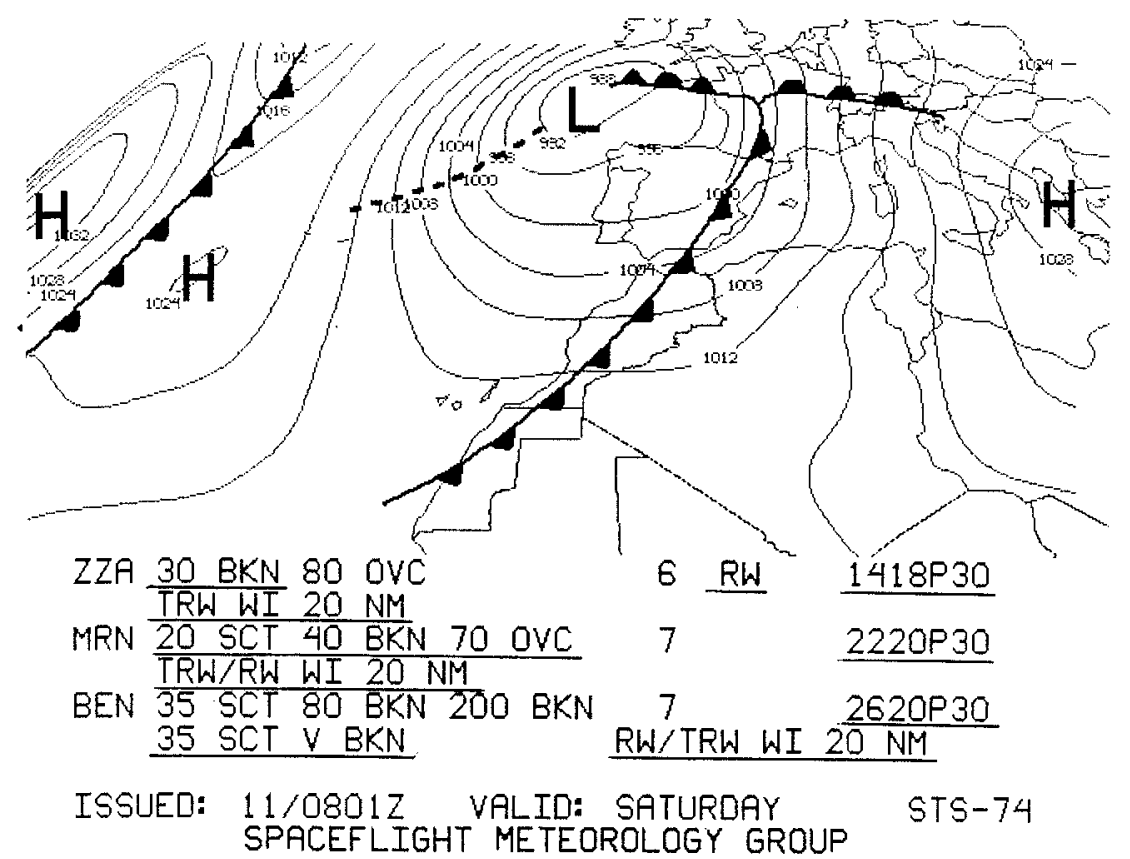

FIG. 3a. SMG 5-h forecast graphic issued at 0800 UTC 11 November 1995 for STS-74 launch attempt. Underlined items denote forecast flight rule violations. Cloud heights are in hundreds of feet, visibility is in statute miles, and wind speed is in knots.

Fig. 3b. Same as Fig. 3a but for TAL sites. 


\section{SPACEFLIGHT METEOROLOGY GROUP}

UPPER WIND FORECAST

VALID: NOV 11, 1995 AT $1321 Z$

STS-74

\begin{tabular}{|c|c|c|c|c|c|c|c|c|c|}
\hline \multirow{2}{*}{ ISSUED: } & \multicolumn{3}{|c|}{ BEN } & \multicolumn{3}{|c|}{ MRN } & \multicolumn{3}{|c|}{$Z Z A$} \\
\hline & \multicolumn{2}{|c|}{$11-11-95$} & $0800 Z$ & \multicolumn{2}{|c|}{$11-11-95$} & $0800 Z$ & \multicolumn{2}{|c|}{$11-11-95$} & $0800 Z$ \\
\hline & $\begin{array}{l}\text { HGT } \\
(\mathrm{FT})\end{array}$ & $\begin{array}{c}\text { DIR/ } \\
\text { (DEG) }\end{array}$ & $\begin{array}{l}\text { SPD } \\
\text { (KTS) }\end{array}$ & $\begin{array}{l}\text { HGT } \\
(\mathrm{FT})\end{array}$ & $\begin{array}{c}\mathrm{DIR} / \\
\text { (DEG) }\end{array}$ & $\begin{array}{l}\text { SPD } \\
\text { (KTS) }\end{array}$ & $\begin{array}{c}\text { HGT } \\
(\mathrm{FT})\end{array}$ & $\begin{array}{c}\text { DIR/ } \\
\text { (DEG) }\end{array}$ & $\begin{array}{c}\text { SPD } \\
\text { (KTS) }\end{array}$ \\
\hline & $60 \mathrm{~K}$ & $260 /$ & 20 & $60 \mathrm{~K}$ & $240 /$ & 30 & $60 \mathrm{~K}$ & $230 /$ & 20 \\
\hline & $50 \mathrm{~K}$ & $240 /$ & 50 & $50 \mathrm{~K}$ & $230 /$ & 35 & $50 \mathrm{~K}$ & $230 /$ & 35 \\
\hline & $38 \mathrm{~K}$ & $240 /$ & 90 & $38 \mathrm{~K}$ & $230 /$ & 80 & $38 \mathrm{~K}$ & $220 /$ & 45 \\
\hline & $28 \mathrm{~K}$ & $240 /$ & 90 & $28 \mathrm{~K}$ & $230 /$ & 75 & $28 \mathrm{~K}$ & $210 /$ & 60 \\
\hline & $20 \mathrm{~K}$ & $240 /$ & 70 & $20 \mathrm{~K}$ & $220 /$ & 70 & $20 \mathrm{~K}$ & $210 /$ & 55 \\
\hline & $12 \mathrm{~K}$ & $240 /$ & 50 & $12 \mathrm{~K}$ & $230 /$ & 50 & $12 \mathrm{~K}$ & $200 /$ & 50 \\
\hline & $10 \mathrm{~K}$ & $240 /$ & 50 & $10 \mathrm{~K}$ & $230 /$ & 50 & $10 \mathrm{~K}$ & $200 /$ & 50 \\
\hline & $7 \mathrm{~K}$ & $240 /$ & 45 & $7 \mathrm{~K}$ & $230 /$ & 45 & $7 \mathrm{~K}$ & $200 /$ & 40 \\
\hline & $5 \mathrm{~K}$ & $240 /$ & 40 & $5 \mathrm{~K}$ & $230 /$ & 45 & $5 \mathrm{~K}$ & $190 /$ & 45 \\
\hline & $3 \mathrm{~K}$ & $240 /$ & 35 & $3 \mathrm{~K}$ & $225 /$ & 35 & $3 \mathrm{~K}$ & $130 /$ & 35 \\
\hline & $2 \mathrm{~K}$ & 2401 & 30 & $2 \mathrm{~K}$ & $225 /$ & 35 & $2 \mathrm{~K}$ & $130 /$ & 35 \\
\hline & $1 \mathrm{~K}$ & $240 /$ & 30 & $1 \mathrm{~K}$ & $225 /$ & 35 & $1 \mathrm{~K}$ & $130 /$ & 35 \\
\hline & SFC & $260 / 20$ & PP30 & SFC & $220 / 2$ & OP30 & SFC & $140 / 1$ & $8 \mathrm{P} 30$ \\
\hline
\end{tabular}

FIG. 4. SMG 5-h upper-wind forecasts issued at 0800 UTC 11 November 1995 for STS-74 launch attempt: BEN = Ben Guerir, Morocco; MRN = Moron, Spain; ZZA = Zaragoza, Spain. launch. The next milestone is the " $\mathrm{L}-1$ " day MMT briefing given about $24 \mathrm{~h}$ prior to launch. The astronaut crew is also given a separate, detailed briefing about 24 $\mathrm{h}$ prior to launch. The "tanking" MMT briefing is given

TABLE 3. SMG entry support timeline.

\begin{tabular}{ll}
\hline \hline Time before TD & \multicolumn{1}{c}{ Event } \\
\hline TD-5 days & EOM forecasts briefed to MMT, flight director \\
TD-4 & EOM forecasts briefed to MMT, flight director \\
TD-3 & EOM forecasts briefed to MMT, flight director \\
TD-2 & EOM forecasts briefed to MMT, flight director \\
TD-1 & EOM forecasts briefed to MMT, flight director \\
TD-1100 h & Flight director briefing \\
TD-900 & SMG entry team arrives \\
TD-630 & EOM forecasts issued \\
TD-515 & Flight director briefing \\
TD-500 & Request GOES rapid scan \\
TD-430 & Weather recon aircraft takeoff \\
TD-400 & Flight director briefing; go/no-go payload \\
& bay door closing decision \\
TD-330 & Weather recon aircraft lands \\
TD-300 & Begin GOES rapid scan \\
TD-240 & Weather recon aircraft takeoff \\
TD-230 & Flight director briefing \\
TD-130 & Flight director briefing; go/no go-deorbit \\
& burn decision \\
TD-100 & Deorbit burn \\
TD-30 min & Flight director briefing \\
TD-15 & Flight dynamics officer briefing \\
TD-07 & Flight dynamics officer briefing; \\
& drag chute deploy decision \\
TD 0 & Landing \\
\hline
\end{tabular}

$\mathrm{TD}=$ shuttle touchdown
$10 \mathrm{~h}$ prior to the scheduled launch time. At this point, the NASA mission management team makes a go or no go decision on whether to fill the external (orange-colored) tank with propellant and proceed with the launch count. Within $6 \mathrm{~h}$ of launch, SMG provides near-continuous weather forecasts, briefings, and updates to the flight director and flight control team on all U.S. landing sites and TAL sites. A separate, detailed weather briefing is provided to the astronaut crew $4 \mathrm{~h}$ prior to launch. Shuttle launch windows vary between $5 \mathrm{~min}$ and $2.5 \mathrm{~h}$, depending on the orbital mechanics and/or payload considerations of the mission. Direct weather support for RTLS ends about 3 min after launch, when a return-tolaunch-site abort landing option ends. Direct weather support for TAL sites ends about 8 min after launch, at main-engine cutoff (MECO), when a transoceanic abort landing is no longer an option. After MECO, the shuttle is committed to enter the "on-orbit" phase of its mission. At that point, the only abort landing options remaining are AOA and 1st Day PLS. If any type of launch abort landing were declared by the flight director, SMG would provide continuous weather updates to the flight director and flight control team until the landing occurred.

\section{2) ON-ORBIT SUPPORT}

During the on-orbit phase, SMG provides forecasts for the next 3 days' landing opportunities at the U.S. landing sites (KSC, EDW, WSSH). These forecasts are 
used by flight controllers to select the daily primary landing site (PLS), which is used for planning in case the shuttle experienced a problem requiring it to deorbit quickly and land. In addition, SMG would provide weather information about emergency landing sites (ELS) around the world if an emergency shuttle landing is required. Occasionally, weather forecasts are provided to support onboard scientific experiment payloads, especially those that require observations of the earth's surface and atmospheric phenomena. Beginning about 5 days before the planned end-of-mission landing, SMG prepares forecasts for the scheduled EOM landing day and for one or two additional contingency days (EOM +1 , EOM + 2). These EOM outlooks are briefed by the mission lead forecaster at the daily MMT meeting. The MMT and flight director typically base their entry (landing) plan on weather forecasts for EOM, EOM + 1 , and EOM +2 . Some shuttle missions have been extended or reduced by a full day, with the decision made 2-3 days in advance, based on SMG's forecasts and briefings. As landing day approaches, SMG's EOM forecasts and briefings become more detailed. Informal, unscheduled briefings to MMT members and flight directors may occur several times daily as EOM draws closer.

\section{3) ENTRY SUPPORT}

Starting about $6 \mathrm{~h}$ before the scheduled landing, SMG provides forecasts, briefings, and updates to the flight director and flight control team on a nearly continuous basis. These briefings support mission control center decision points such as the shuttle's payload bay door closing $4 \mathrm{~h}$ before landing and the astronaut crew "suitup" at $3 \mathrm{~h}$ before landing. SMG's most critical forecast and briefing is made just prior to the deorbit burn decision. This final "go" or "no-go" forecast is issued directly to the flight director about 90 min prior to the scheduled landing. This time interval is to allow the shuttle to maneuver into deorbit burn position, complete the burn, reenter the atmosphere, and land. Once the deorbit burn has been initiated, the shuttle must land at the chosen site at the designated time. The only changes possible are the choice of the final approach path and the choice of runways at the designated landing site. The shuttle is essentially an unpowered glider on descent. After the deorbit burn there is no option to "go around" for another landing attempt. This 90-min forecast must be precise, accurate, and clearly communicated in order for NASA flight directors to make wellinformed, safe landing decisions. There are usually two or three landing opportunities on a given EOM landing day. A typical scenario provides two landing opportunities at KSC and one at EDW. The two KSC opportunities would be separated by about $90 \mathrm{~min}$ (the time it takes the shuttle to orbit the earth once and land). The first EDW landing opportunity would either be on the same revolution as the second $\mathrm{KSC}$ opportunity, or could be on the following (third) revolution. If a "waveoff" of the first KSC landing opportunity occurs based on observed and/or forecast weather flight rule violations, the flight director may then decide for the shuttle to attempt a landing at the next opportunity at either $\mathrm{KSC}$ or EDW, requiring another 90-min go/no-go weather assessment by SMG. If the weather remains unacceptable, the flight director may opt to wave-off the landing until the next day. For most missions, NASA assigns a higher priority to landing at the preferred site than to landing on the first EOM day. Thus a forecast of go weather for the next day at the primary landing site normally takes precedence over go conditions on the current day at the alternate landing site, given that the option exists to extend the mission and land on the $\mathrm{EOM}+1$ or $\mathrm{EOM}+2$ day.

\section{Data acquisition and display}

SMG provides mesoscale analysis and forecasts for locations scattered around the globe. This creates unique requirements for data acquisition, processing, and display. Two systems perform these functions for SMG: the Meteorological Information and Data Display System (MIDDS) and the WSR-88D Principal User Process (PUP).

\section{a. $M I D D S$}

MIDDS integrates a wide variety of data sources for interactive display by SMG meteorologists. In addition, forecasters use the MIDDS to create briefing graphics and disseminate these products to the Flight Control Team and MMT. The MIDDS is based on the Space Science and Engineering Center's McIDAS system (Suomi et al. 1983; Rotzoll et al. 1991; Young and Fox 1994). McIDAS software provides data acquisition and display capability for surface and upper-air observations, forecasts, and bulletins, as well as numerical model data. In addition, McIDAS provides a programming interface to extend the system's capabilities. The flexibility of the software has allowed the MIDDS to integrate nearly all required data into a single display system. Table 4 summarizes all MIDDS data sources. The following paragraphs will describe the application of some of the MIDDS data sources to spaceflight weather support.

\section{1) WeAther SATEllite}

Satellite images provide a critical source of data for landing forecasts. The SMG satellite ingest workstations receive real-time digital GOES-8, GOES-9, and Meteosat- 6 data. The direct ingest of the GOES satellite data provides SMG access to "rapid scan" (roughly 7.5-min interval) or "super rapid scan" (down to 1-min interval) infrared and visible satellite imagery from $G O E S-8$ and GOES-9. Hourly GOES-8 and GOES-9 sounder data are 
TABLE 4. MIDDS data sources.

\begin{tabular}{lll}
\hline \hline \multicolumn{1}{c}{ Data type } & \multicolumn{1}{c}{ Location } & \multicolumn{1}{c}{ Ingest source } \\
\hline Surface observations & Worldwide & IDS, DDS+, and USAF AWN \\
Upper-air observations & Worldwide & IDS, DDS+, and USAF AWN \\
Text bulletins & Worldwide & IDS, DDS+, and USAF AWN \\
GOES-8 & Eastern United States/full disk & Direct satellite downlink \\
GOES-9 & Western United States/full disk & Direct satellite downlink \\
Meteosat-6 & Europe/Africa/full disk & Satellite downlink via Wallops Island, VA \\
NCEP gridded models & Worldwide & Local NCEP ingest and HRS \\
NCEP profile archive & Selected locations worldwide & Local NCEP ingest \\
Rawinsonde & Kennedy Space Center & Direct data circuit \\
Jimsphere (windsonde) & Kennedy Space Center & Direct data circuit \\
50-MHz Doppler wind profilers & Kennedy Space Center & Direct data circuit \\
Tower mesonetwork & Kennedy Space Center & Direct data circuit \\
Cloud-to-ground lightning location & Kennedy Space Center & Direct data circuit \\
Electric field mill data & Kennedy Space Center & Direct data circuit \\
Rawinsonde & Edwards Air Force Base & Direct data circuit \\
Tower mesonetwork & Edwards Air Force Base & Direct data circuit \\
Rawinsonde & White Sands Space Harbor & Direct data circuit \\
Tower mesonetwork & White Sands Space Harbor & Direct data circuit \\
Rawinsonde & TAL sites & Direct data circuit \\
Automated surface observations & TAL sites & Direct data circuit \\
\hline
\end{tabular}

USAF $=$ United States Air Force.

AWN $=$ Automated Weather Network.

HRS $=$ High Resolution Data Services.

NCEP $=$ National Centers for Environmental Prediction.

also received and stored, although techniques to apply the sounder data to spaceflight support are still evolving. Meteosat-6 images covering the TAL sites are received each half-hour.

SMG receives rapid scan imagery starting approximately $3 \mathrm{~h}$ prior to each launch and landing. SMG meteorologists track mesoscale features using animation of rapid scan imagery to determine likely areas of cloud formation and dissipation, especially convective clouds. Conventional and mesoscale observations can be superimposed on the satellite images to enhance the mesoscale analyses.

Satellite imagery is also essential for complete evaluation of the weather flight rules. Satellite imagery is used to monitor the development, movement, and dissipation of low clouds, convective storms, and anvil cirrus. Additionally, satellite imagery is used to determine cloud-top temperatures, which are related to potential for electrification. The 3.9- and 11.2- $\mu \mathrm{m}$ GOES channels have been used to improve capabilities to detect, track, and forecast areas of fog and low clouds at night (Ellrod 1995).

\section{2) NUMERICAL MODELS}

SMG receives numerical model output including the medium-range forecast model (MRF), aviation model (AVN), Eta Model:Meso-Eta Model, and Nested Grid Model (NGM), and Rapid Update Cycle (RUC). In addition, SMG uses the NGM, AVN, and MRF profile archives (Plummer 1989) to provide vertical profiles of the numerical guidance at shuttle landing sites. The NGM profile archive provides hourly forecast thermo- dynamic and wind profiles for the landing sites for the first $48 \mathrm{~h}$ of the forecast period. The AVN model provides forecast profiles at 6-h intervals for projections out to 3 days, and the MRF provides forecast profiles at 12-h intervals for projections out to 10 days. These profiles are used most by SMG for forecasts projections greater than $6 \mathrm{~h}$. For forecasts projections less than $6 \mathrm{~h}$ a mesoscale model is desirable to supplement trend analysis from observational data. SMG has evaluated the Mesoscale Atmospheric Simulation System (MASS) model covering Florida run by the Applied Meteorology Unit (AMU) at KSC. The MASS model was found to be less effective than the RUC in predicting shuttle weather flight rule criteria (Manobianco et al. 1996). A major deficiency in the MASS appeared to be the lack of concentrated data needed for initialization. Developing a mesonetwork observing system across Florida and including other datasets like WSR-88D and profilers into initialization of a mesoscale model will be necessary before mesoscale modeling outperforms current NCEP models in Florida. SMG is participating in an AMU project to assess the utility of the $29-\mathrm{km}$ mesoEta Model for spaceflight weather support.

\section{3) UPPER-AIR MEASUREMENTS}

A combination of direct and remote sensing equipment is used to make upper-air measurements for space shuttle support. Upper-air sounding data are taken at frequent intervals in the hours just before launch and landing at all potential U.S. and TAL landing sites. The $50-\mathrm{MHz}$ Doppler wind profiler at KSC provides a sample of the upper-air winds every $5 \mathrm{~min}$ at altitudes from 
about 6000 to $60000 \mathrm{ft}$. A network of five $915-\mathrm{MHz}$ Doppler wind profilers with Radio Acoustic Sounding Systems was recently installed in the KSC area (Heckman et al. 1995). The $915-\mathrm{MHz}$ profiler network will provide detailed wind and virtual temperature measurements from about 500 to $10000 \mathrm{ft}$. Weather reconnaissance performed by astronauts flying aircraft at the landing sites provides valuable information concerning clouds, winds, turbulence, visibility, and precipitation. This information is a critical supplement to radar and satellite data for tracking weather changes within about $4 \mathrm{~h}$ of launch and landing.

In addition to evaluating the state of the atmosphere, the upper-air measurements are a key to predicting the atmosphere's effects on the shuttle trajectory during landing. SMG forecasters use the observed winds and model profile archives to create the upper wind and turbulence forecasts for each of the U.S. and TAL landing sites (Bellue et al. 1996). The ascent and descent analysis teams at JSC incorporate the observed winds and SMG forecasts into shuttle ascent load models and descent trajectory models. That output is then used by the flight control team to ensure the safe flight of the vehicle during ascent and during planned or emergency landings.

\section{4) LightNING LOCATION AND ATMOSPHERIC ELECTRIC FIELD}

The lightning strike to the Apollo 12 spacecraft in 1969 spurred interest in lightning research at KSC. KSC is now one of the best-instrumented locations in the world for monitoring the atmospheric electric field and lightning (Maier et al. 1995). A network of magnetic direction finders detects and locates cloud-to-ground lightning in the vicinity of KSC (Krider et al. 1976). Forecasters use the cloud-to-ground lightning data in conjunction with WSR-88D data to determine if thunderstorms are occurring within $30 \mathrm{n} \mathrm{mi}$ of the SLF and to help determine when anvil cirrus clouds become detached from the parent cumulonimbus cloud. Although no weather flight rules pertain to the electric field values, the MIDDS can access the Launch Pad Lightning Warning System (LPLWS) data to monitor the atmosphere's electric field. The LPLWS can be a valuable system for detecting the electrification of clouds near the SLF.

\section{5) Mesonet data}

In addition to the conventional data sources, NASA supports extensive mesoscale surface networks at KSC, WSSH, and EDW. As an example, over 40 meteorological-instrumented towers are included in the KSC network with each tower reporting temperature, dewpoint, and both average and peak wind measurements at several levels between 10 and $54 \mathrm{ft}$ above ground level. In addition, some mesonet towers provide measurements up to $492 \mathrm{ft}$ at KSC and $120 \mathrm{ft}$ at EDW. These mesonet towers are vital for analyzing and tracking wind shift lines like the sea breeze at KSC. This is important for forecasting convective initiation/dissipation as well as crosswinds, headwinds, and tailwinds. Temperature and relative humidity data from the towers also aid in forecasting the development and dissipation of fog or low stratus clouds, which can be critical forecast parameters for shuttle landings at KSC.

\section{b. WSR- $88 D$}

SMG's WSR-88D PUP associated to NWSO Melbourne, Florida (KMLB), was one of the first NWS PUPs delivered, in 1992. The greater sensitivity and capability of the WSR-88D radar allows improved detection of most weather features compared with preWSR-88D radars (Crum and Alberty 1993). This increased capability has improved SMG's ability to monitor and forecast weather for shuttle support. SMG has used the WSR-88D data operationally to support over 36 space shuttle missions.

Another source of radar data for the KSC area is from the Patrick AFB, Florida, WSR-74C radar, which is enhanced by a McGill processor (Austin et al. 1986). This enhanced radar data is transferred from the Cape Canaveral MIDDS to the JSC/SMG MIDDS, where it may be readily displayed on MIDDS.

The uniqueness of the shuttle weather flight rules causes SMG to utilize the WSR-88D data differently than most other weather offices. For example, the WSR$88 \mathrm{D} 0.5^{\circ}$ base reflectivity product occasionally detects cloud drops and cloud streets. This assists SMG in monitoring and forecasting cloud cover amount and low cloud ceiling development in the KSC area. Lowestlevel base reflectivity and velocity products are valuable for locating sea-breeze boundaries, convective outflow boundaries, and other fine lines, which help with tracking wind shifts and forecasting convective initiation and dissipation. Higher-level base reflectivity products and layer composite reflectivity products are used to track movement and location of thunderstorm anvils, which have specific avoidance limits in shuttle weather flight rules. Echo thunderstorm anvils top products are used to monitor convective cell development. Finally, $0.5^{\circ}$ base reflectivity and velocity products are both used in detecting and confirming chaff and tracking its movement.

Chaff affecting central Florida was first documented by SMG with the use of the WSR-88D in 1993 (Hermes 1993). Since chaff can "mask" reflectivity returns of precipitation and cloud streets, it has been recognized as a potential problem for analysis and forecasting of shuttle launch and landing weather parameters. Coordination procedures were placed into effect in 1994 by the Department of Defense to stop chaff drops prior to shuttle launches and landings (Roeder 1995).

Another unique aspect of SMG WSR-88D utility is the use of "switch" software on the PUP to accomplish 

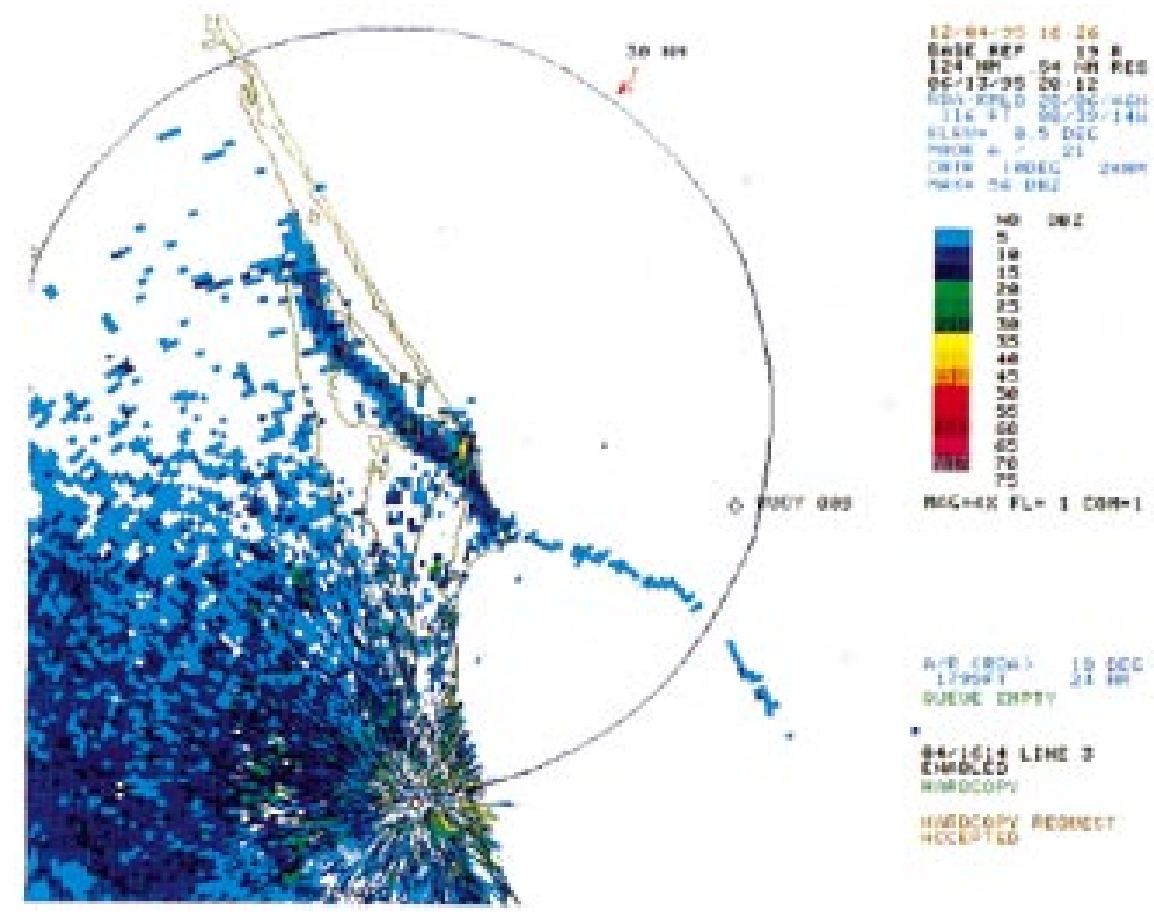

FIG. 5. Melbourne, FL, WSR-88D 0.5 base reflectivity, 2012 UTC 13 June 1995.

SMG's requirement for dual PUP association to two different sites. This software was developed by the WSR-88D Operational Support Facility (OSF) and was installed in 1994. Association to KMLB is required to support space shuttle landing weather forecasts, while association to NWSO Houston-Galveston, Texas (KHGX), is required for issuance of local JSC weather advisories.

SMG has set up a special set of user functions that allows acquisition of data from two WSR-88D sites at the same time. This is accomplished by continually dialing out to one site while being associated to the other site, allowing data from both KMLB and KHGX to be displayed and manipulated at the same time on SMG's PUP. This feature has been valuable during space shuttle missions for monitoring KMLB and Edwards AFB (KEYX) WSR-88D data when landing weather forecasts are required for both sites.

Figure 5 shows a KMLB $0.5^{\circ}$ base reflectivity product taken during SMG's support of a shuttle deorbit simulation on 13 June 1995. This figure illustrates the WSR88D's utility in diagnosing low-1evel boundaries. An unusual boundary is depicted in the 5-15 dBZ reflectivites. This boundary extends from north of the KSC area southward along the coast to near Cape Canaveral, then southeast into the Atlantic. The sea breeze is responsible for this boundary from Cape Canaveral northward, while the boundary southeast of the cape is of unknown origin. The ease of identifying these boundaries and tracking their movement with the PUP is a valuable diagnostic and forecasting capability.

\section{Examples of launch and landing forecast scenarios}

Virtually each shuttle mission presents a different set of meteorological challenges for shuttle weather forecasters. Below are descriptions of mission forecast scenarios that illustrate the variety and scope of weather forecast issues and challenges. For more in-depth meteorological descriptions, please refer to Hafele and Haller (1991) for TAL weather support, and Bellue and Tongue (1995) and Bellue and Garner (1995) for U.S. landing site weather support descriptions section 4a describes launch scenarios and section $4 \mathrm{~b}$ describes landing scenarios where weather forecasts were a critical factor in mission success.

\section{a. Launch day impacts of landing weather}

1) STS-74 LAUNCH ATTEMPTS: 11 AND 12 NOVEMBER 1995 (TAL WEATHER)

For the STS-74 (Atlantis) launch attempt of 11 November 1995, U.S. landing site weather (Fig. 1) for RTLS, AOA, and 1st Day PLS weather was observed and forecast go. The TAL weather observations and forecasts were no go for all three usable northern sites (Fig. 2). Within launch minus $6 \mathrm{~h}$, weather flight rule violations for tailwind, cloud ceilings, and rain showers were observed and forecast for Zaragoza, Spain. At Moron, Spain, and Ben Guerir, Morocco, cloud ceiling and crosswind violations were observed and forecast. Since the STA-74 mission was scheduled to rendezvous with 


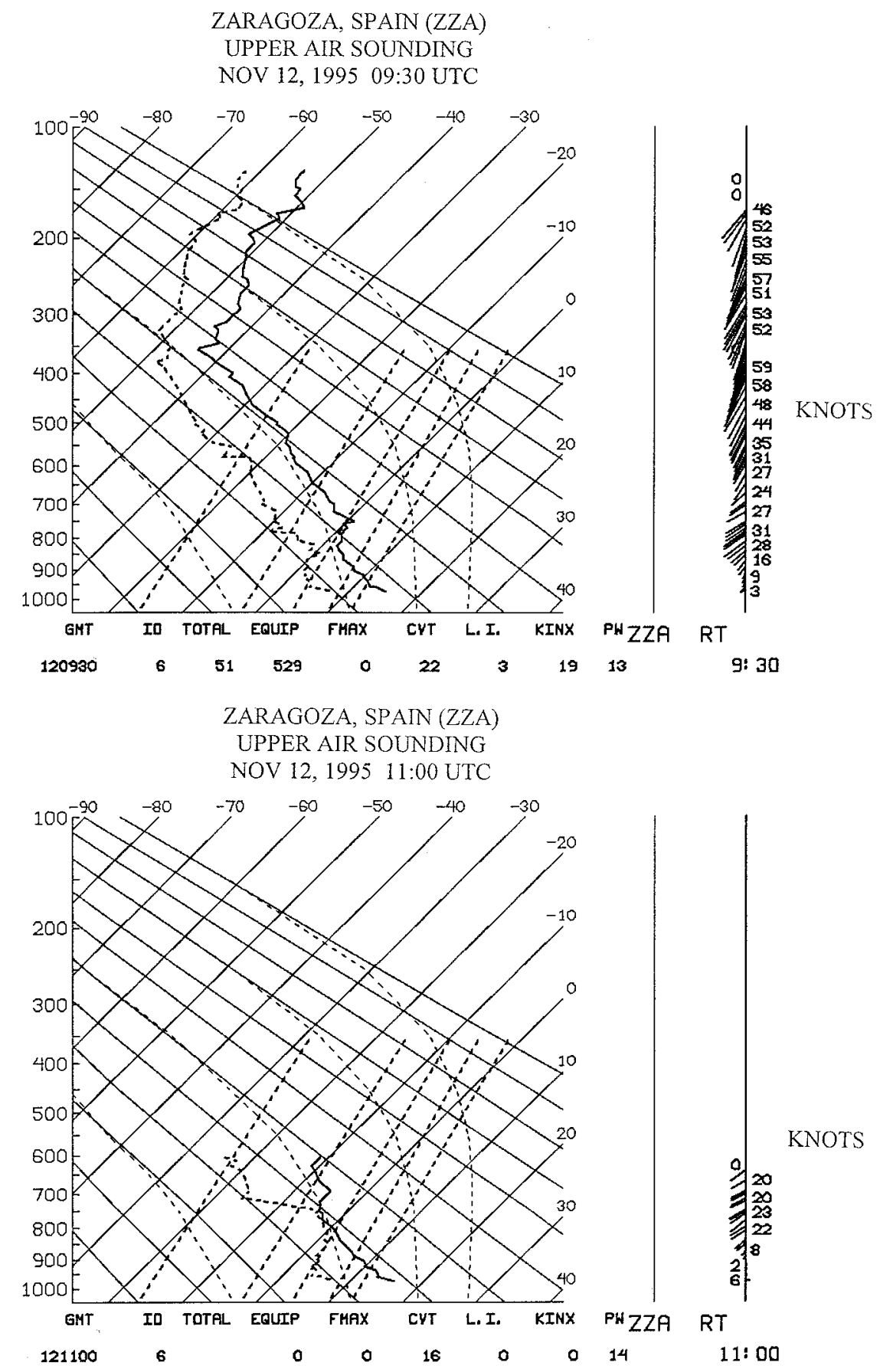

FIG. 6. Zaragoza, Spain, rawinsonde, (a) 0930 UTC 12 November 1995, and (b) 1100 UTC 12 November 1995.

the Russian Mir space station, the launch opportunity window was only 7 min long. No-go TAL observations and forecasts continued through the launch countdown. The launch was "scrubbed" (i.e., postponed) for $24 \mathrm{~h}$ due to lack of an acceptable TAL site. This marked only the second time in the history of the space shuttle program that a launch was scrubbed based only on no-go TAL weather.
On the next day, 12 November 1995, weather at Moron, Spain, and Zaragoza, Spain, improved to go within $1 \mathrm{~h}$ of the scheduled 1230 UTC launch time. Meteosat satellite imagery, frequent rawinsonde releases, and weather reconnaissance aircraft reports played an important part in assessing TAL site weather on this day. Weather concerns for Zaragoza were cloud ceilings, precipitation, and tail wind exceedance. Rawinsonde re- 


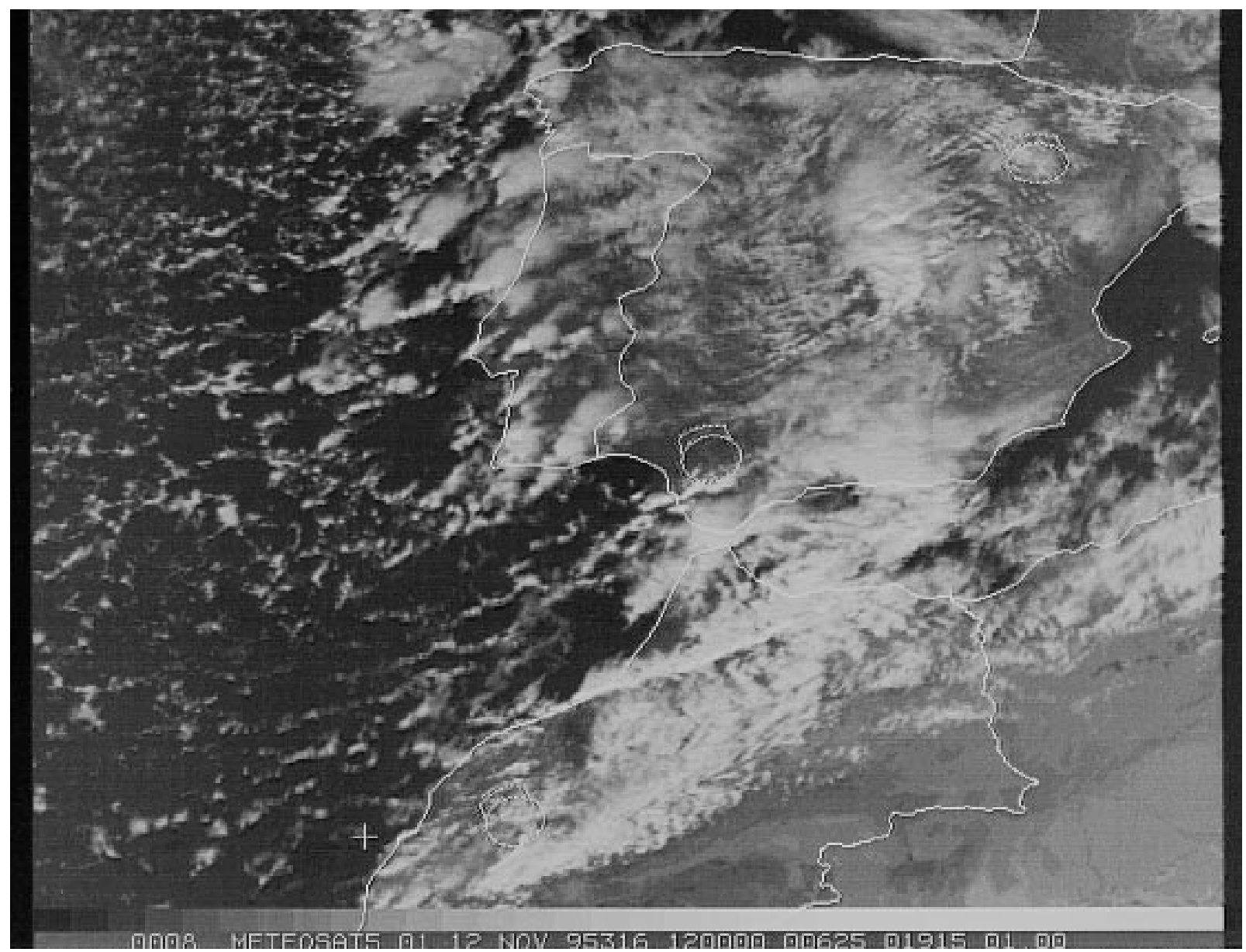

FIG. 7. Meteosat 1-km visible image, 1200 UTC 12 November 1995.

leases leading up to the launch time (Figs. 6a and 6b) showed that winds aloft, which could mix down to the surface, were decreasing in speed as the launch time drew near. Surface observations and satellite imagery animation showed increasing clouds in the hours leading up to launch. However, weather aircraft reconnaissance reports at Zaragoza noted no obstructions to pilot visibility on approach and no rain or virga within $20 \mathrm{n} \mathrm{mi}$ of the landing site. Astronaut-piloted weather reconnaissance aircraft observations may take priority over those by ground-based observers since the aircraft is following the shuttle flight path and makes a direct measurement of slant-range visibility. Zaragoza weather became go just prior to launch.

Satellite imagery animation and weather reconnaissance aircraft reports were the basis for amending the Moron forecast to go. Bands of showers and thunderstorms were moving ashore in southwestern Spain. Meteosat imagery animation was crucial for forecasting the formation, curvilinear motion, rapid speed, and dissipation of these showers. However, satellite navigation and parallax errors potentially could have made the Moron weather no go since dissipating rain showers were very close to the edge of the $20 \mathrm{n}$ mi weather flight rule limit for precipitation. Figure 7 shows the 1200 UTC Meteosat satellite image. Weather reconnaissance aircraft reported that the observed location of the showers was just beyond the $20 \mathrm{n} \mathrm{mi}$ weather flight rule limit. With two go TAL sites, Atlantis was given the go for launch.

\section{2) STS-36 LAUNCH: 28 FEBRUARY 1990 (RADAR, WEATHER RECON AIRCRAFT)}

Attempting to launch around midnight local time, the STS-36 (Atlantis) launch on 28 February 1990 was delayed because of forecast ceiling and rain flight rule violations for RTLS at KSC and ceiling violations at the TAL sites. The launch count was held at $\mathrm{T}$ minus $5(\mathrm{~T}-5) \mathrm{min}$ for launch pad weather (launch commit criteria weather violations), RTLS weather, and TAL weather. Through the launch count, cloud ceilings at KSC remained between 3000 and $5000 \mathrm{ft}$ in rain showers and ranged from 5500 to $7500 \mathrm{ft}$ outside the areas of precipitation. A late report from the weather reconnaissance aircraft indicated that the runway landing aids 


\section{KENNEDY SPACE CENTER (KSC) \\ UPPER AIR SOUNDING \\ SEPT 18, 1995 09:11UTC}

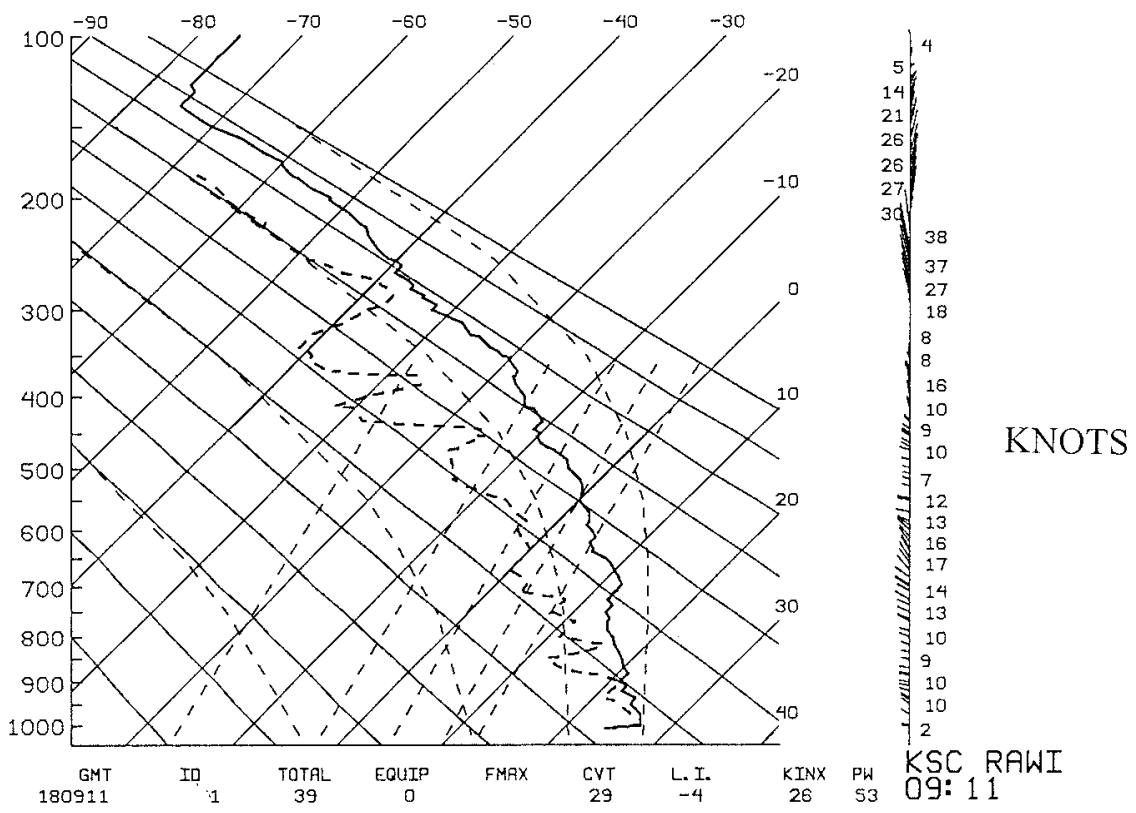

FIG. 8. Kennedy Space Center rawinsonde, 0911 UTC 18 September 1995.

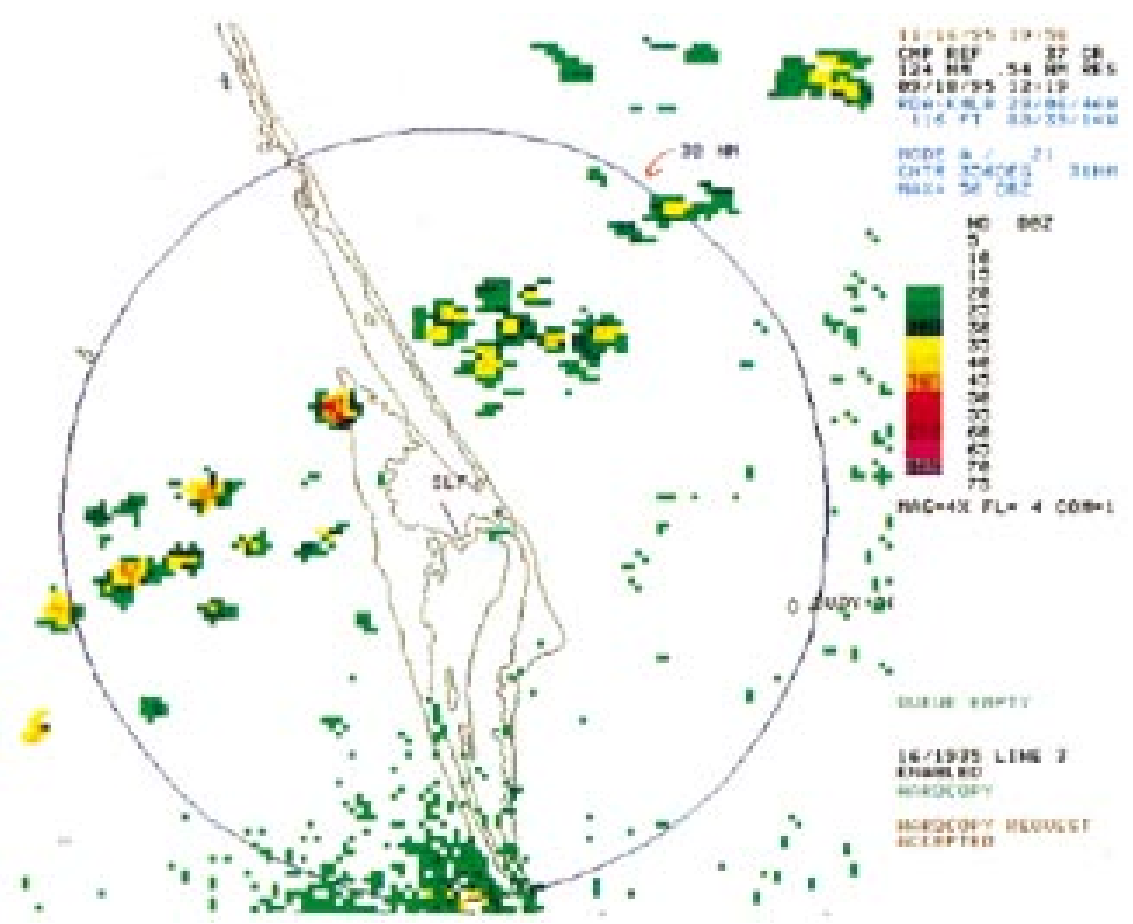

FIG. 9. Melbourne, FL, WSR-88D composite reflectivity, 1219 UTC 18 September 1995. 


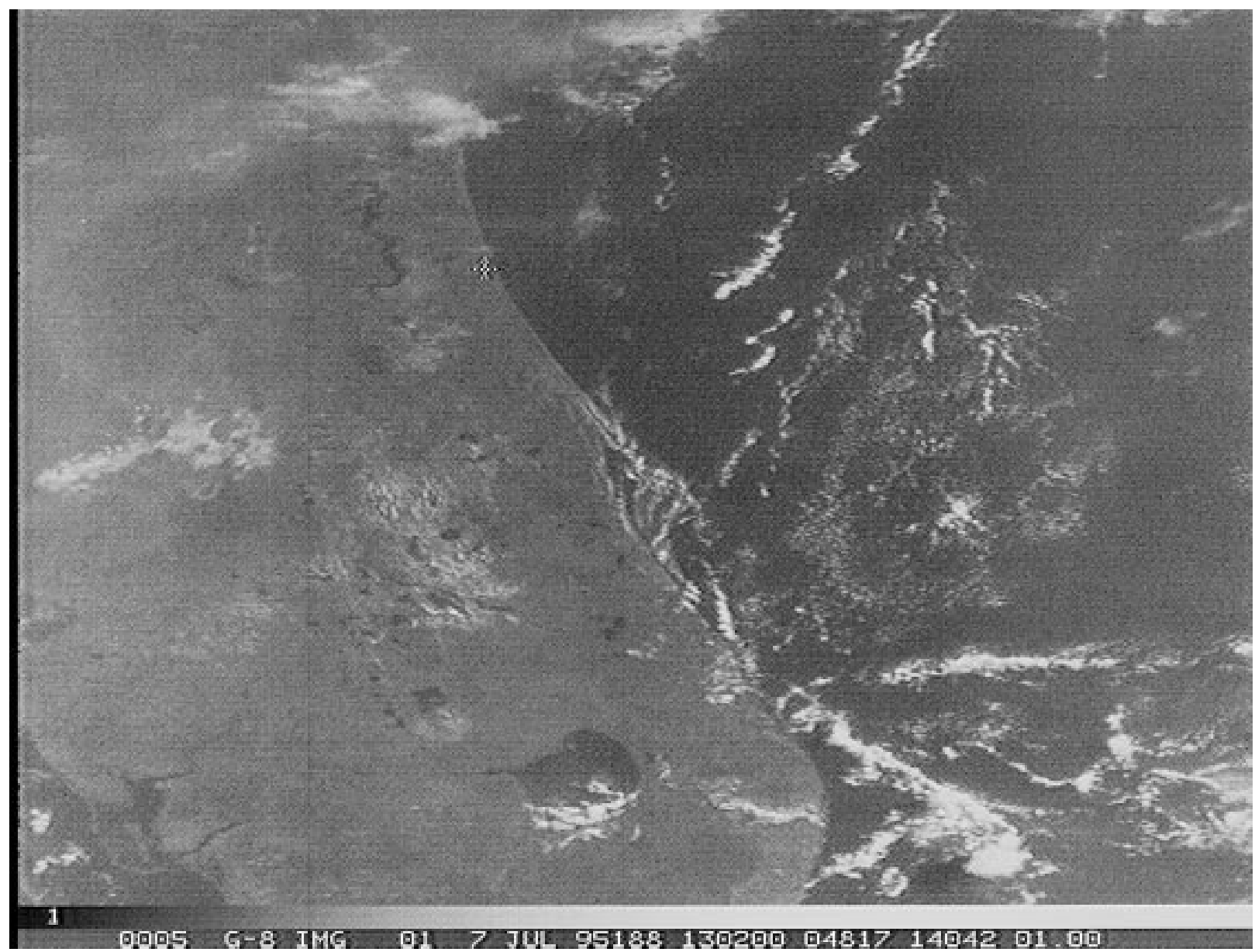

FIG. 10. GOES-8 1-km visible image, 1302 UTC 7 July 1995.

were visible at $8000 \mathrm{ft}$ due to the cloud translucence even while the aircraft was in the bases of the cloud layer. Infrared satellite imagery depicted a broad overcast cloud deck across central Florida. Banded rainshowers were moving through the area. Based on WSR$74 \mathrm{C}$ radar data from Patrick Air Force Base, SMG predicted that one band of rain showers would move out of the 20-n mi flight rule limit area before another band moved into the 20-n mi area. Forecast timing of the movement of the rainshower bands and reports from the weather reconnaissance aircraft at $\mathrm{KSC}$, as well as improving TAL weather conditions, gave forecasters confidence to update forecasts to go for RTLS and TAL. STS-36 launched successfully with 5 min remaining in the 2.5-h launch window.

\section{b. Landing day impacts}

1) STS-69 LANDING WEATHER: 18 SEPTEMBER 1995 (CLOUDS, SHOWERS, FOG)

For the STS-69 (Endeavor) landing, a weak surface trough was located just north of KSC. The primary forecast concerns for the KSC morning landing opportu- nities were visibilities reduced by fog for the first landing opportunity near sunrise (1138 UTC) and low clouds or rain shower development for the second opportunity (1314 UTC). Weather flight rules in effect at that time for EOM landings at KSC stipulated cloud ceilings above $10000 \mathrm{ft}$, visibility of $5 \mathrm{n} \mathrm{mi}$ or greater, and no rainshowers or thunderstorms within $30 \mathrm{n}$ mi. Figure 8 shows the 0911 UTC 18 September 1995 KSC sounding. The low-level inversion along with light west to northwest low-level winds and high moisture content indicated possible fog development. Additionally, this high moisture content and an unstable air mass indicated the potential for rainshower and thunderstorm development. As deorbit burn decision time approached, weather reconnaissance aircraft reports and local surface observations indicated little fog development around KSC. SMG determined that the convective temperature was unlikely to be reached until after the first scheduled landing opportunity. SMG updated the forecast at the deorbit burn decision point to reflect go conditions for the first landing opportunity. However, the forecast remained no go for the second landing opportunity due to expected development of low cloud ceilings and rain- 


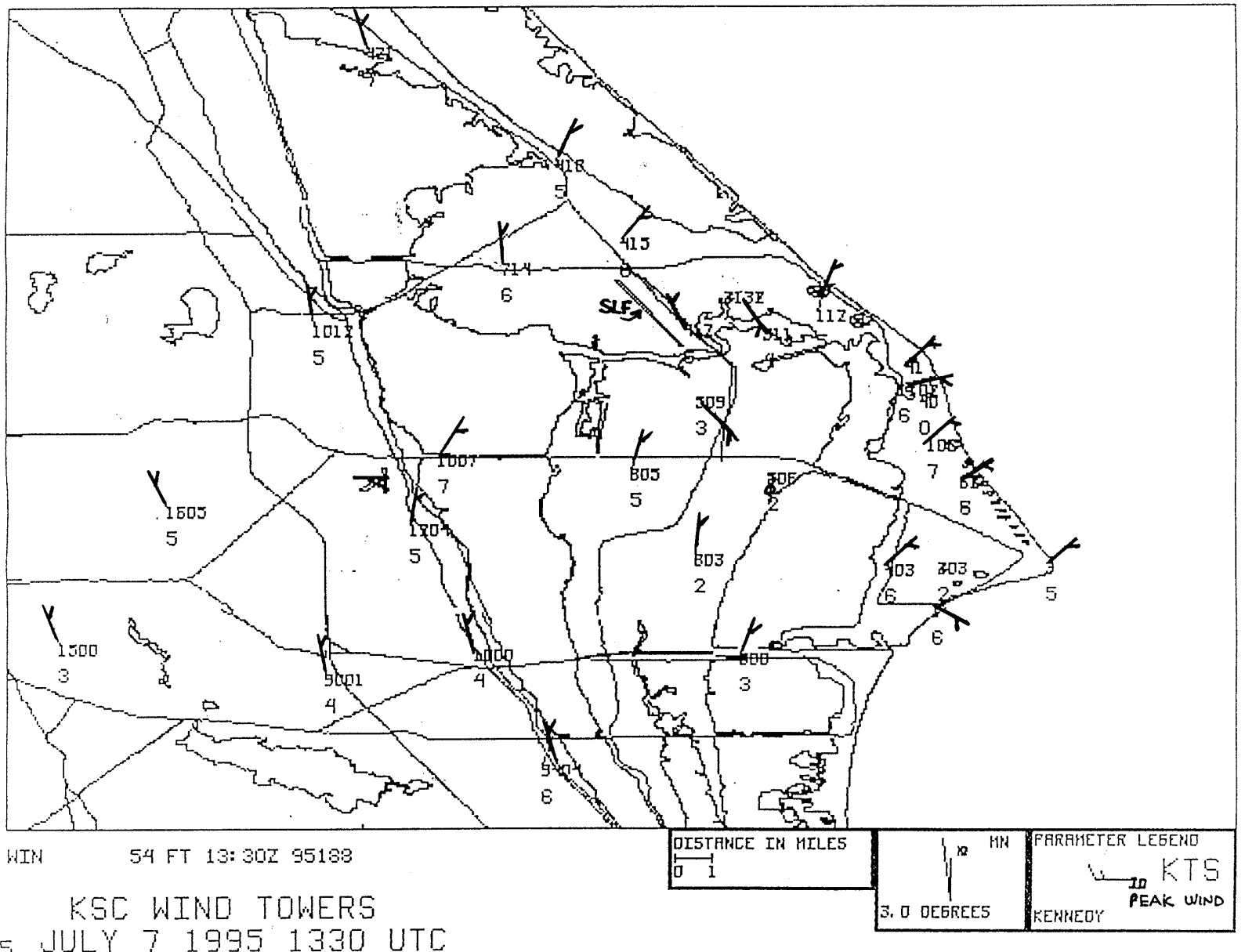

FIG. 11. Kennedy Space Center mesonet 54-ft wind tower data, 1330 UTC 7 July 1995.

showers. Based on SMG's updated forecast, the flight director gave a go for the deorbit burn for the first landing opportunity and the shuttle landed safely at $\mathrm{KSC}$ at 1138 UTC. Rainshowers developed within $30 \mathrm{n} \mathrm{mi}$ of KSC just 20 min after landing, and weather remained no go through what would have been the second KSC landing opportunity. Figure 9 shows a WSR-88D composite reflectivity product valid 40 min after landing, showing the development of the showers along the surface trough near KSC. In this case, the weather reconnaissance reports, timely upper-air soundings, and the forecaster's experience with local convective climatology were critical in SMG's ability to confidently forecast go conditions for the first landing opportunity and no-go conditions for the second opportunity.

\section{2) STS-71 LANDING (LOW CLOUDS, SEA BREEZE)}

The STS-71 (Atlantis) landing day, 7 July 1995, began with clear skies. The SMG landing forecast for 1455 UTC called for scattered low clouds at KSC. Shuttle weather flight rules in effect at that time for KSC EOM landings required forecast cloud layers below $10000 \mathrm{ft}$ to be scattered (5/10 coverage or less). Additionally, for KSC only, weather flight rules in effect at the time stipulated $2 / 10$ or less observed cloud coverage below $10000 \mathrm{ft}$ at the deorbit burn decision time $90 \mathrm{~min}$ before landing. The midmorning sea breeze was expected to develop and push the clouds west of the KSC SLF. The 1055 UTC KSC sounding showed an increase in lowlevel moisture but drier air above $3000 \mathrm{ft}$. This indicated an increased potential for low cloud development and coverage but also implied limited vertical development. Low clouds with 3/10 sky coverage developed at the SLF around 1300 UTC (Fig. 10). The sea breeze also developed as depicted in the KSC wind tower mesonet (Fig. 11) but was weak and slow to move inland. Thus, the low clouds were not being pushed west of the SLF as fast as expected. At the 1330 UTC deorbit burn decision point, based on weather reconnaissance aircraft reports, surface observations, local mesonet tracking of the sea breeze, and experience with KSC sea-breeze and cloud development patterns, SMG advised the flight director that the clouds would indeed remain only scattered at the SLF, even though 3/10 low cloud coverage was observed. Based on the confidence expressed in 


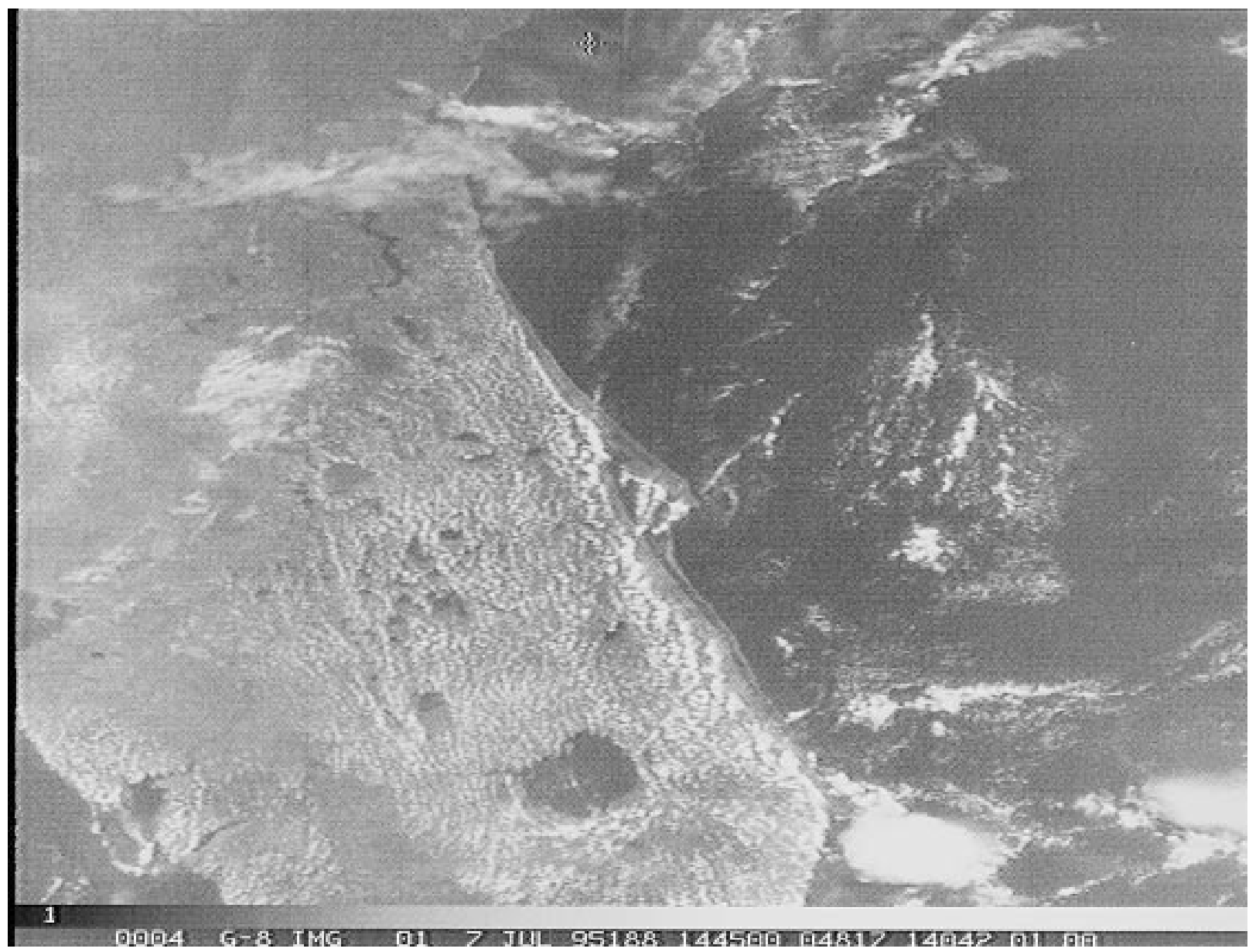

FIG. 12. GOES-8 1-km visible image, 1445 UTC 7 July 1995.

this go forecast, the flight director decided to "waive" the $2 / 10$ observed cloud flight rule and deorbit. The shuttle landed safely at 1455 UTC 7 July 1995, with scattered clouds at $2700 \mathrm{ft}$ covering $3 / 10$ of the sky at landing time (Fig. 12).

\section{3) STS-67 LANDING AT EDWARDS AFB (WINDS)}

STS-67 (Endeavor) was scheduled to land at KSC on 17 March 1995. Showers and thunderstorms in the KSC area prevented a landing during all three KSC landing opportunities. Thus, Endeavor's landing was waved-off and the shuttle and seven-person astronaut crew spent one more day in orbit. On 18 March 1995, showers and thunderstorms were forecast for the KSC area. SMG forecasters at the Mission Control Center in Houston coordinated with the National Severe Storms Forecast Center in Kansas City. This forecast coordination helped SMG convince the NASA flight control team and MMT that landing at KSC was not safe that day, and the decision was made to land at EDW. However, crosswinds were a prime weather concern at EDW for the 2047 UTC scheduled landing time. At the deorbit burn decision time, the peak crosswinds on
EDW Runway 22 varied between 11 and $15 \mathrm{kt}$, just within the 15-kt crosswind limit. SMG forecasters assimilated weather information from a mesoscale network of wind towers, frequent weather balloon releases, and military weather observers at EDW, to accurately forecast that winds would remain within shuttle crosswind limits for the shuttle's touchdown time. SMG forecast experience with local wind circulations around the EDW lakebed runway complex (Hafele and Garner 1993) was critical in the development of this landing forecast and in the confidence of that forecast expressed to the flight director. EDW wind tower plots at the deorbit burn time (1923 UTC) and at landing time (Figs. 13a and 13b) indicate the variability of the EDW lakebed winds. Endeavor landed safely at 2047 UTC 18 March 1995. Surface crosswinds winds at landing time were $8 \mathrm{kt}$, well within crosswind limits.

\section{Summary}

The Spaceflight Meteorology Group is an integral part of the shuttle flight control team. SMG provides critical landing weather support to the Mission Control Center at JSC and the Space Shuttle Program. This support is quite 

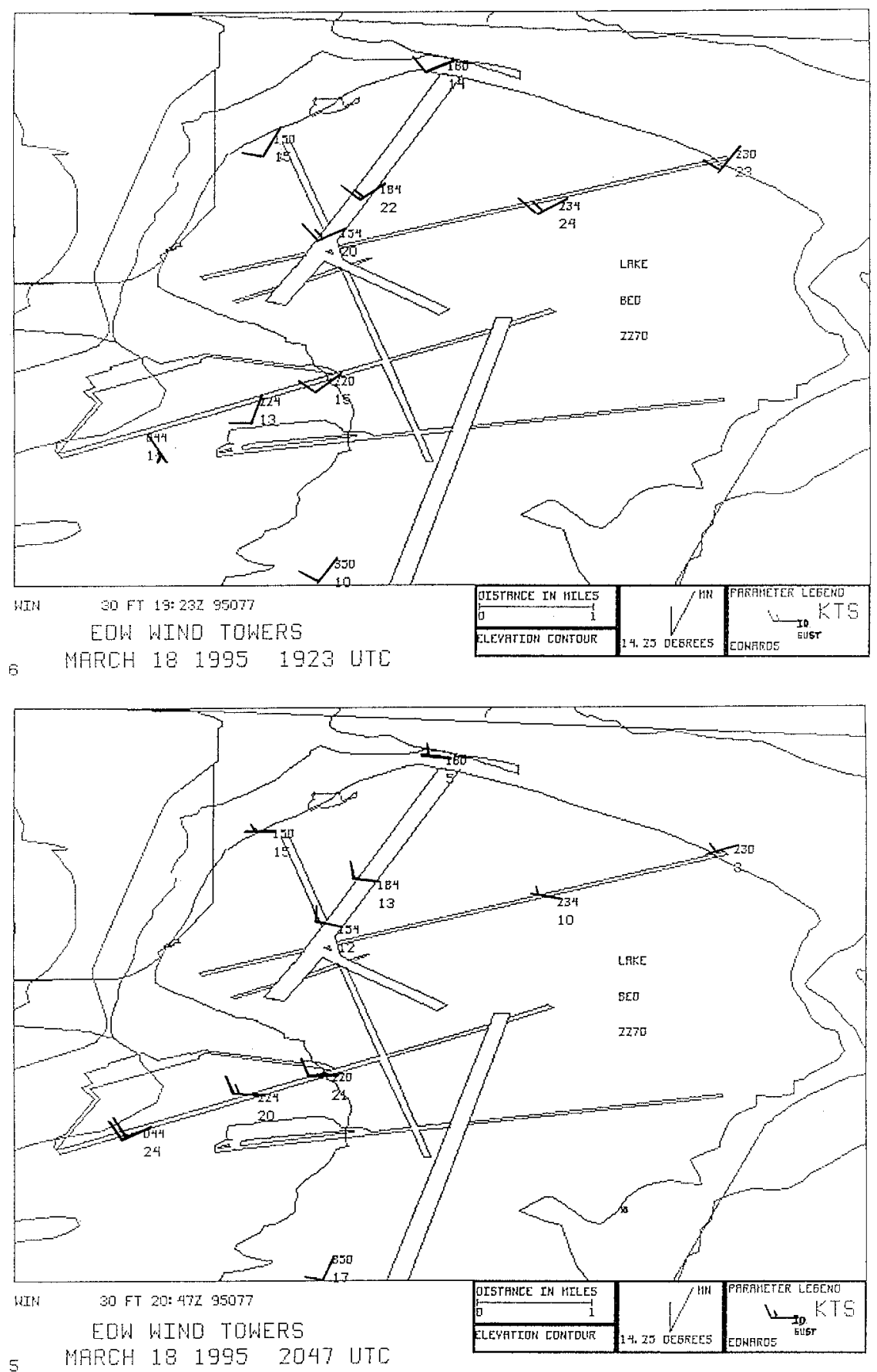

FIG. 13. Edward Air Force Base mesonet 30-ft wind tower data, (a) 1923 UTC 18 March 1995, and (b) 2047 UTC 18 March 1995.

complex and specialized. It requires a meteorologica1 team skilled and experienced in forecasting, computer technology, and understanding specific customer requirements. The ongoing challenge is to apply the latest developments in technology and meteorological knowledge to unique shuttle weather support requirements, in order to maintain and improve the quality of analyses, forecasts, and weather advice. This, in turn, will allow NASA to maintain and improve its ability to make safe, smart, and cost-effective weather-related shuttle launch and landing decisions.

\section{Future work}

SMG will be exploring and reviewing systems and techniques, including data assimilation models, for more effective integration of the steadily increasing volume 
of meteorological data. Also, in conjunction with NCEP and the Applied Meteorology Unit, SMG will continue to evaluate and eventually incorporate mesoscale models and ensemble forecast techniques (Tracton and Kalnay 1993) into its operations. These initiatives will occur in combination with ongoing case studies and evaluations of shuttle landing weather scenarios.

Other future work will focus on becoming more completely integrated into the Mission Control Center, facilitating increased two-way electronic transfer of weather and flight control information between SMG and the Flight Control Team. A new challenge is the very short (5-15 min) launch windows required for rendezvous with the Russian Mir space station and with the upcoming construction of the international space station. SMG will continue working with the flight control team and Space Shuttle Program to help evaluate and refine weather flight rules to maximize launch and landing opportunities and maintain a safe environment for shuttle abort and end-of-mission landings.

Acknowledgments. Dan Smith of NWS Southern Region Headquarters provided the original motivation for this article and assisted greatly in the review process. The authors would like to thank SMG staff members Wayne Baggett, Tim Garner, Cara Heist, Mark Keehn, Doris Rotzoll, Karl Silverman, and Steve Sokol for their contributions to, and reviews of, the manuscript. Deborah Kessler of NASA/Johnson Space Center, John Madura of NASA/Kennedy Space Center, and Herb Brody of MIT Technology Review provided helpful reviews. Monica Sowell of SMG provided superior assistance in preparing tables and figures. The comments of two anonymous reviewers and Dr. Bradley Colman were quite valuable in improving this paper. Interested readers are invited to visit the SMG Web site at http://shuttle.nasa.gov/weather/smghome.html.

\section{APPENDIX}

\section{Acronym List}

1st Day PLS First-day primary landing sites 45WS United States Air Force 45th Weather Squadron

$\begin{array}{ll}\text { AMU } & \text { Applied Meteorology Unit } \\ \text { AOA } & \text { Abort-once-around } \\ \text { AVN } & \text { Aviation model } \\ \text { CCAS } & \text { Cape Canaveral Air Station } \\ \text { DDS+ } & \text { Domestic Data Service }+ \\ \text { EDW } & \text { Edwards Air Force Base } \\ \text { ELS } & \text { Emergency landing sites } \\ \text { EOM } & \text { End-of-mission } \\ \text { GOES } & \text { Geostationary Orbiting Environmental } \\ & \text { Satellite } \\ \text { IDS } & \text { International Data Service } \\ \text { JSC } & \text { Johnson Space Center } \\ \text { KHGX } & \text { NWSO Houston/Galveston, Texas }\end{array}$

\begin{tabular}{|c|c|}
\hline KMLB & NWSO Melbourne, Florida \\
\hline $\mathrm{KSC}$ & Kennedy Space Center \\
\hline $\mathrm{LCC}$ & Launch Commit Criteria \\
\hline LPLWS & Launch Pad Lightning Warning System \\
\hline MASS & $\begin{array}{l}\text { Mesoscale Atmospheric Simulation Sys- } \\
\text { tem }\end{array}$ \\
\hline $\mathrm{MCC}$ & Mission Control Center \\
\hline MECO & Man-engine cutoff \\
\hline McIDAS & $\begin{array}{l}\text { Man-Computer Interactive Direct Ac- } \\
\text { cess System }\end{array}$ \\
\hline MIDDS & $\begin{array}{l}\text { Meteorological Interactive Data Display } \\
\text { System }\end{array}$ \\
\hline MMT & Mission Management Team \\
\hline MRF & Medium-range forecast \\
\hline NASA & $\begin{array}{l}\text { National Aeronautics and Space Admin- } \\
\text { istration }\end{array}$ \\
\hline NCEP & $\begin{array}{l}\text { National Center for Environmental Pre- } \\
\text { diction }\end{array}$ \\
\hline NGM & Nested Grid Model \\
\hline NOAA & $\begin{array}{l}\text { National Oceanic and Atmospheric Ad- } \\
\text { ministration }\end{array}$ \\
\hline NWS & National Weather Service \\
\hline OSF & Operational Support Facility \\
\hline PLS & On-orbit primary landing sites \\
\hline PUP & Principal User Processor \\
\hline RTLS & Return to launch site \\
\hline RUC & Rapid update cycle \\
\hline SLF & Shuttle Landing Facility \\
\hline SMG & Spaceflight Meteorology Group \\
\hline TAL & Transoceanic abort landing \\
\hline TDU & Techniques Development Unit \\
\hline UTC & Universal time coordinated \\
\hline WSR-74C & Weather Surveillance Radar-74C \\
\hline WSR-88D & Weather Surveillance Radar-88D \\
\hline WSSH & White Sands Space Harbor \\
\hline
\end{tabular}

\section{REFERENCES}

Austin, G. L., A. Kilambi, A. Bellon, N. Leoutsarakos, A. Hausner, L. Trueman, and M. Ivanich, 1986: Rapid II: An operational, highspeed interactive analysis and display system for intensity radar data processing. Preprints, Joint Sessions 23d Conf. on Radar Meteorology and Conf. on Cloud Physics, Snowmass, CO, Amer. Meteor. Soc., 79-82

Bellue, D. G., 1993: Spaceflight Meteorology Group evolution of the daily simulation forecast verification effort. Preprints, Fifth Int. Conf. on Aviation Weather Systems, Atlanta, GA, Amer. Meteor. Soc., 372-375.

— - and T. W. Garner, 1995: Nowcasting for shuttle weather support during the STS-59 mission. Preprints, Conf. on Aviation Weather Systems, Dallas, TX, Amer. Meteor. Soc., 286-291.

- and J. S. Tongue, 1995: Use of the WSR-88D for space shuttle weather support during the STS-57 and STS-51 missions. Natl. Wea. Dig., 19(3), 16-25.

— , K. B. Batson, and T. D. Oram, 1996: Forecasting upper winds for the space shuttle. Preprints, 12th Int. Conf. on Interactive Information and Processing Systems for Meteorology, Oceanography, and Hydrology, Atlanta, GA, Amer. Meteor. Soc., 256260.

Boyd, B. F., W. P. Roeder, J. B. Lorens, D. S. Hazen, and J. W. Weems, 1995: Weather support to pre-launch operations at the Eastern 
Range and Kennedy Space Center. Preprints, Sixth Conf. on Aviation Weather Systems, Dallas, TX, Amer. Meteor. Soc., 135140.

Brody, F. C., 1993: Operations of the Spaceflight Meteorology Group. Preprints, 13th Conf. on Weather Analysis and Forecasting, Vienna, VA, Amer. Meteor. Soc., 189-193.

Crum, T. D., and R. L. Alberty, 1993: The WSR-88D and the WSR88D operational support facility. Bull. Amer. Meteor. Soc., 74, $1669-1687$.

Ellrod, G. P., 1995: Advances in the detection and analysis of fog at night using GOES multispectral infrared imagery. Wea. Forecasting, 10, 606-619.

Ernst, J. A., and F. J. Merceret, 1995: The Applied Meteorology Unit: A tri-agency applications development facility supporting the space shuttle. Preprints, Sixth Conf. on Aviation Weather Systems, Dallas, TX, Amer. Meteor. Soc., 266-269.

Hafele, G. M., and D. J. Haller, 1991: Tools used to forecast weather at TAL sites during STS-41. Preprints, Seventh Int. Conf. on Interactive Information and Processing Systems for Meteorology, Oceanography, and Hydrology, New Orleans, LA, Amer. Meteor. Soc., 36-41.

_ , and T. W. Garner, 1993: Planned use of a meteorological mesonetwork to assist forecasting the weather conditions at Edwards Air Force Base for space shuttle landings. Preprints, Fifth Int. Conf. on Aviation Weather Systems, Atlanta, GA, Amer. Meteor. Soc., 35-39.

Heckman, S. T., M. W. Maier, W. P. Roeder, J. B. Lorens, and B. F. Boyd, 1995: The operational use of a boundary layer profiler network at the Eastern Range and Kennedy Space Center. Preprints, 27th Conf. on Radar Meteorology, Vail, CO, Amer. Meteor. Soc., 346-348.

Hermes, L. G., 1993: Chaff observations with WSR-88D: Examples and operational impacts. Preprints, Second NWS National Aviation Weather Workshop, Boulder, CO, National Weather Service, 43-48.

Krider, E. P., R. C. Noggle, and M. A. Uman, 1976: A gated, wideband magnetic direction finder for lightning return strokes. J. Appl. Meteor., 15, 301-306.

Maier, M. W., L. M. Maier, and C. Lennon, 1995: Lightning detection and location systems for spacelift operations. Preprints, Sixth Conf. on Aviation Weather Systems, Dallas, TX, Amer. Meteor. Soc., 292-297.

Manobianco, J. T., J. W. Zack, and G. E. Taylor, 1996: Workstationbased real-time mesoscale modeling designed for weather support to operations at the Kennedy Space Center and Cape Canaveral Air Station. Bull. Amer. Meteor. Soc., 77, 653-672.

NASA/JSC, 1997a: NASA Operational Shuttle Flight Rules (NSTS 12820), Final June 6, 1996, PCN-4 May 1, 1997, Vol. A, section 2.1.1-6. NASA/Johnson Space Center, 2-11-2-33. [Available from JSC/DA8, Houston, TX 77058.]

— 1997b: NASA Space Shuttle Launch Commit Criteria and Background (NSTS 16007), Chapter 4, May 15, 1997; Chapter 5, August 28, 1996. NASA/Kennedy Space Center, 4-1-4-15 and 5-1-5-7. [Available from JSC/AP4, Houston, TX 77058.]

Plummer, D. W., 1989: Diagnostic and forecast graphics products at NMC using high frequency model output. Wea. Forecasting, 4, 83-89.

Roeder, W. P., 1995: Operational impacts and identification of chaff on weather radar. Preprints, 27th Conf. on Radar Meteorology, Vail, CO, Amer. Meteor. Soc., 373-375.

Rotzoll, D. A., S. J. Cunningham, and E. K. Hogan, 1990: Evolution of MIDDS II in JSC space shuttle operations. Preprints, Seventh Int. Conf. on Interactive Information and Processing Systems for Meteorology, Oceanography, and Hydrology, New Orleans, LA, Amer. Meteor. Soc., 48-53.

Suomi, V. E., R. Fox, S. S. Limaye, and W. L. Smith, 1983: McIDAS III: A modern interactive data access and analysis system. $J$. Climate Appl. Meteor., 22, 766-778.

Tracton, M. S., and E. Kalnay, 1993: Operational ensemble prediction at the National Meteorological Center: Practical aspects. Wea. Forecasting, 8, 379-398.

Young, J. T., and R. J. Fox, 1994: Future plans for McIDAS workstations. Preprints, Workshop on Meteorological Operation Systems, Reading, United Kingdom, ECMWF, 240-247. 